\title{
INFORMACIÓN BIOLÓGICA: ¿LA TEORÍA DE LA INFO RMACIÓN ATACA DE NUEVO?
}

\author{
MARÍA FERREIRA RUIZ \\ https://orcid.org/0000-0002-6931-1072 \\ Primary affiliation \\ University of Buenos Aires \\ Department of Philosophy \\ Ciudad Autónoma de Buenos Aires \\ Argentina \\ Secundary affiliation \\ Université de Genève \\ Department of Philosophy \\ Geneva \\ Switzerland \\ mariaferreiraruiz@gmail.com
}

\section{Article info \\ CDD: 574.01}

Received: 08.07.2018; Revised: 10.12.2018; Accepted: 04.02.2019

DOI: http://dx.doi.org/10.1590/0100-6045.2019.V42N1.MR

\section{Keywords}

Biological information

Causal specificity

Informational functions

Information theory

DNA-environment distinction

\section{Palabras Clave}

Información biológica

Teoría de la información

Especificidad causal

Intervencionismo

Biología molecular 


\begin{abstract}
The philosophy of biology literature offers several arguments aimed at showing that information theory is conceptually unsuited to capture the informational talk in molecular biology. Such arguments led to the consensus that, if the informational talk in biology can be defended and explained at all, we need a different strategy. The debate, in fact, developed mostly along this line. However, recent contributions seem to (and even daim to) challenge the consensus and thus to vindicate the role and relevance of information theory to this particular debate. In this paper, I examine the main arguments leading to such a consensus and I analyze the extent to which those recent accounts actually succeed in vindicating the invocation of information theory. I argue that these attempts fail to vindicate the information-theoretic strategy and, therefore, the consensus remains unaffected by them.
\end{abstract}

Resumen: La literatura filosófica ha ofrecido una serie de argumentos que buscan mostrar la inadecuación conceptual de la teoría de la información para capturar el modo como el concepto se usa en biología molecular. A partir de éstos, se llegó a cierto consenso de que si acaso hay alguna forma de explicar y defender el concepto de información en biología molecular, la estrategia debe ser otra, y el debate continuó principalmente persiguiendo alternativas. Sin embargo, algunos aportes recientes parecen desafiar el consenso y revigorar la discusión en torno a la relevancia de la teoría de la información en este contexto. El objetivo de este trabajo es analizar los argumentos que condujeron a dicho consenso y examinar en qué medida estas propuestas logran vindicar la apelación a la teoría de la información. Argumentaré que induso la propuesta más refinada en esta línea falla en vindicar la estrategia teórico-informacional y que, como consecuencia, el consenso todavía puede ser defendido.

\title{
1. INTRODUCCIÓN
}

Una de las principales discusiones en filosofía de la biología molecular concierne al uso de nociones 
informacionales para describir ciertas biomoléculas y su rol causal en el desarrollo de los seres vivos. De hecho, el propio campo de la biología molecular se consolidó de la mano de la idea de información: el ADN contiene información para el desarrollo y, esta información se transmite de generación en generación mediante mecanismos de herencia. Esta "visión heredada" del ADN y los mecanismos genéticos puede encontrarse con sólo abrir cualquier manual de biología molecular.

Sin embargo, desde un punto de vista filosófico, hay varios aspectos en esta visión heredada que pueden ser puestos en duda o que requieren un examen más cuidadoso. No sólo por razones de índole teórica-biológica (qué implica, desde el punto de vista teórico, una caracterización informacional de ciertas macromoléculas), sino también porque información se dice de muchas maneras en distintos contextos teóricos y disciplinares, más allá de lo que suceda al interior de la biología misma. En filosofía de la biología, en particular, el problema en torno al concepto de información en biología molecular ha sido formulado de diversas maneras. Sin embargo, hay una pregunta que es fundamental: si 'información’ es un término polisemántico (Floridi 2014), ¿en qué sentido se habla de información en biología molecular? Para responder a esta pregunta, se han intentado distintos abordajes. Algunos han tomado un enfoque que podemos llamar importacionista, consistente en dar cuenta del uso de nociones informacionales en biología molecular a partir de un concepto de información que pertenece a una teoría previamente constituida, y típicamente externa a la biología. Por el contrario, otros asumen un enfoque no importacionista, con la intención de reconstruir un concepto de información sui generis a partir de su uso en el contexto particular de la biología molecular.

La estrategia importacionista ha asumido que la más cabal teoría de la información es la que debemos a Claude 
Shannon (1948), o al menos eso parece seguirse del hecho de que otras teorías prácticamente no han sido tenidas en cuenta en el debate filosófico en torno a la idea de información biológica. Y si bien ésta no es la única teoría de la información disponible, sí ha sido quizás la más reconocida y utilizada en contextos relativos a las comunicaciones. En efecto, en los comienzos de la era de la biología molecular, se dio por hecho que la biología molecular no hablaba sino de información à la Shannon -al menos, en el ámbito científico (aunque cierto grado de confusión era también explícitamente reconocido).

Una buena parte de los interlocutores en el debate filosófico, en cambio, han puesto en duda la adecuación de la teoría de la información para capturar la idea de información en biología. A partir de una serie de argumentos y objeciones a la estrategia importacionista, el debate arribó a cierto consenso filosófico de que si acaso había alguna forma de explicar y defender el concepto de información en biología molecular, la estrategia para ello debía ser no importacionista. El debate, entonces, se desarrolló principalmente en esta última línea. Sin embargo, algunos aportes muy recientes parecen desafiar el consenso y revigorar la discusión en torno a la estrategia importacionista, sugiriendo que la teoría de la información es, después de todo, más relevante para la discusión de lo que suele reconocerse.

En este trabajo, me ocupo exclusivamente de la estrategia importacionista. El objetivo es analizar los argumentos que condujeron al consenso antiimportacionista y examinar en qué medida, realmente, logran aquellas recientes propuestas vindicar la teoría importacionista via teoría de la información. La tesis que defenderé es que incluso la propuesta más refinada en esta línea falla en vindicar la estrategia importacionista y que, como consecuencia, el consenso todavía puede ser 
defendido. El trabajo se articula como sigue. En la sección 2, presento el problema en torno a la noción de información en biología. En la sección 3, explico las distintas estrategias para abordarlo. Las objeciones contra la estrategia importacionista son analizadas a continuación, en la sección 4. Luego, en la sección 5 , presento propuestas recientes que podrían ser vistas como vindicando la estrategia importacionista, y argumento por qué a pesar de todo no lo logran. La sección 6 cierra el artículo con recapitulaciones y conclusiones.

\section{UN PROBLEMA, DOS ESTRATEGIAS PARA ABORDARLO}

El uso del concepto de información está muy extendido en biología y aparece en las formulaciones teóricas más importantes de la biología molecular, tales como el "dogma central" (Crick 1958, P. 153). La visión heredada en biología sostiene que el ADN contiene información para el desarrollo del organismo y que esta información se transmite o hereda de generación en generación. El ADN es comúnmente conceptualizado como una molécula informacional y los principales procesos genéticos se explican o expresan en lenguaje informacional: la información almacenada en el ADN se copia en el proceso de replicación, se transfiere al ARN mediante el proceso de transcripción, y del ARN a la proteína mediante el proceso de traducción. Pero que estas descripciones sean las usuales no implica que resulte del todo claro qué significa el término 'información' en biología o que su referencia sea obvia; antes bien, todo lo contrario. Por un lado, la biología no cuenta con nada semejante a una "teoría de la información biológica" $\mathrm{y}$, por el otro, el término 'información' no es patrimonio exclusivo del vocabulario 
biológico, sino que aparece en una abrumadora diversidad de contextos (ver por ejemplo Adriaans 2013).

Pero para introducir el problema conviene comenzar explicando en qué sentido no hay un problema con la idea de información en biología. El concepto de información se usa en sentido epistémico cuando decimos que (nosotros, agentes con capacidades cognitivas) tenemos información acerca de un mecanismo genético siendo investigado. Este sentido de información es muy próximo al sentido cotidiano de información (asociado a nociones como la de contenido semántico o datos), trasciende la biología, y no es el que origina problemas para la filosofía de la biología en particular. Luego hay otro sentido que parece más óntico que epistémico, como cuando decimos que una célula produce, consume, contiene, transmite, interpreta, (etc.) información. Esto es algo que el sistema biológico "hace" independientemente de nuestro conocimiento sobre ello. Ambos sentidos corren paralelamente y no están conectados de ninguna forma evidente o interesante.

Es el segundo sentido el que desata toda clase de problemas. Para algunos, implica compromisos respecto de nuestro entendimiento de los mecanismos genéticos y de cómo actúan ciertas moléculas en el desarrollo que no encuentran apoyo en la evidencia empírica, tales como una "supremacía" causal genética. Para otros, equivale a reificar una noción abstracta en la ausencia de una buena justificación metafísica, algo que podría incluso ser rastreado y conectado con el pasado vitalista de la biología. Algunos filósofos han entonces argumentado que el lenguaje informacional en biología no es literal sino metafórico o ficcional (Griffiths 2000; Fox Keller 2003; Levy 2011). De ser así, el problema debería ser reconducido o subsumido bajo aquél más general en torno al uso de metáforas en ciencias (Hallyn 2000), y al menos una de las líneas del debate llegaría a su fin. Pero la situación no es tan 
simple y, de acuerdo con otros autores, hay en biología un sentido de 'información' legítimo que no es metafórico ni epistémico, que puede y requiere ser elucidado y explicado.

Asumiendo que el concepto de información en biología no tiene un carácter simplemente ficcional, sino que hay algún sentido más literal, el problema filosófico se presenta en los siguientes términos:

(1) Fundamentalmente, el problema es de elucidación, puesto que 'información' es un término extraordinariamente equívoco.

(2) Implica también un problema de criterio. La elucidación debe sensible al hecho de que no todo en biología molecular se representa como conteniendo o transmitiendo información, de modo que debe ser operacionalizable para poder determinar en qué casos una estructura biológica contiene información (digamos, un gen) y otra estructura no (por ejemplo, una proteína estructural).

(3) $\mathrm{Y}$ tiene asociado un problema de justificación, ya que ninguna defensa positiva del concepto de información en biología molecular se sigue automáticamente de una elucidación operacionalizable (podría resultar eliminable o teóricamente inadecuado).

En los debates que se han dado sobre el tópico se pueden reconocer dos estrategias diferentes para abordar el problema: una que he decidido llamar importacionista y otra, opuesta a la primera, que podemos denominar no importacionista. 
La estrategia importacionista busca comprender y elucidar la noción de información genética apelando a una teoría de la información previamente disponible y externa a la biología. Existen diversas teorías de la información desarrolladas en el contexto de las comunicaciones, y dada su indiscutida utilidad en sus propios dominios, es ciertamente razonable tomarlas en cuenta y analizar si 'información' significa lo mismo en contextos teóricos comunicacionales y en biología molecular. Tomar esta estrategia, pues, implica asumir dos supuestos generales:

(i) Que teorías semejantes ofrecen una noción de información que podemos considerar satisfactoria y clara.

(ii) Que teorías semejantes son relevantes o significativas para dar cuenta de la noción de información genética.

Ambos supuestos pueden y han sido cuestionados.

La estrategia no importacionista, por el contrario, busca reconstruir y defender nociones de información sui generis que apuntan a dar cuenta del modo específico cómo se habla de información en ciertos contextos biológicos. En esta estrategia, a diferencia de lo que ocurre con la importacionista, subyace un supuesto más general, a saber, que la biología molecular no habla de 'información' en un sentido comunicacional y que, por lo tanto, de nada sirve apelar a una teoría de la información para explicar el habla informacional en biología. La idea es, entonces, atender 
exclusivamente a la práctica biológica para determinar qué significa 'información' en este contexto ${ }^{1}$.

En los últimos años, la literatura sobre el tema ha favorecido la estrategia no importacionista, y se han defendido diversas conceptualizaciones alternativas de la idea de información biológica. En general, este consenso está basado en una serie de argumentos que intentan mostrar la incompatibilidad conceptual entre la teoría de la información y el modo como los biólogos utilizan este concepto (cf. Sección 4). No obstante, la estrategia importacionista aún tiene algunos defensores (cf. Sección $5)$.

\section{LA ESTRATEGIA IMPORTACIONISTA VÍA TEORÍA DE LA INFORMACIÓN}

La historiadora de la ciencia Lily Kay (2000) sostiene que durante la mayor parte del siglo XX hubo un extendido "discurso de la información", que estuvo motivado, en parte, por la propuesta de varias teorías formales de la

\footnotetext{
${ }^{1}$ Los enfoques dentro de esta estrategia son muy diversos y sus virtudes y defectos no pueden ser analizados en este artículo. Ver por ejemplo los enfoques teleosemántico (Maynard Smith 2000a, 2000b; Jablonka 2002, Kumar 2014), instruccional (Stegmann 2005), mecanístico (Bogen y Machamer 2011, Kjosavik 2014), representacional (Shea 2007, 2011a, 2011b), semiótico (Sarkar 2004, 2005c), basado en signaling games (Planer 2014, 2016; Calcott 2014), y biosemiótico (Emmeche 1991, 1999; Hoffmeyer 2008), además de las propuestas ficcionalistas (Fox Keller 2003, Levy 2011) y deflacionistas (Šustar 2007).
} 
información. Estas teorías resultaron exitosas en sus dominios y generaron optimismo generalizado respecto de sus aplicaciones. Un caso notable es la teoría desarrollada por Claude Shannon en 1948, en su artículo " $A$ Mathematical Theory of Communication". Esta teoría, ocupada en la optimización de los recursos y medios para transmitir información de la manera más eficiente, revolucionó el campo de las comunicaciones.

La biología (en particular, la biología molecular), por su parte, se vio permeada por el vocabulario informacional típico de la época de un modo bastante explícito. Naturalmente, desde el punto de vista filosófico, se suscitó la pregunta de si acaso la teoría de Shannon y la biología molecular hablan de información en el mismo sentido o, en términos más precisos, si acaso la teoría de Shannon sirve para elucidar el concepto de información tal como es usado en biología, volviendo tales usos mucho más técnicos.

\subsection{Conceptos fundamentales de la teoría de la información de Shannon}

En su origen, la teoría de Shannon buscó solucionar algunos problemas técnicos relativos a las telecomunicaciones. En particular, Shannon mostró que, contra lo que se creía entonces, aumentar la tasa de transmisión de información en un canal comunicativo no aumentaba la probabilidad de error, siempre que esa tasa estuviera por debajo de la capacidad del canal. Uno de los puntos esenciales de la teoría es que la capacidad del canal y la cantidad de información transmitida pueden ser cuantificadas.

La teoría tiene aplicación en situaciones comunicacionales donde se pueden identificar cinco 
componentes, fácilmente reconocibles en situaciones cotidianas (tal como en una comunicación telegráfica):

1. Una fuente $(F)$, que produce los mensajes (en el ejemplo, una secuencia de letras).

2. Un transmisor, que opera sobre el mensaje de modo que produce una señal adecuada para ser transmitida mediante un canal, es decir, lo codifica (en el ejemplo, los puntos, líneas y espacios en un telégrafo).

3. Un canal $(\mathrm{CH})$, que sirve de medio para la transmisión de la señal desde el transmisor hasta el receptor (un cable).

4. El receptor $(R)$, que realiza la operación inversa respecto del transmisor, reconstruyendo $\mathrm{O}$ decodificando el mensaje a partir de la señal.

5. El destinatario, persona o cosa a la cual el mensaje se dirige.

F y R se caracterizan por poder asumir distintos estados dentro de un rango de estados posibles con determinadas probabilidades de ocurrencia y se dan correlaciones sistemáticas entre F y R. La intuición básica de la teoría es que cuanto menor es la probabilidad de que un mensaje generado en $\mathrm{F}$ sea recibido en $\mathrm{R}$, el valor informacional del mensaje será más alto. Desde el punto de vista de la teoría, no importa si un mensaje es en efecto transmitido, sino que lo relevante son las probabilidades condicionales que tienen los mensajes de ser emitidos por la fuente y recibidos por el receptor. 
Hay dos aspectos de la teoría que resultan clave (cuanto menos, en tanto que la distinguen de otras teorías semejantes). En primer lugar, la teoría lidia con cantidades promedio de los estados de un sistema y con sus probabilidades, no con mensajes individuales. En segundo lugar, la teoría no lidia con el contenido o significado de los mensajes. El artículo de Shannon comienza, prácticamente, desestimando los aspectos semánticos vinculados a la información. En uno de los fragmentos más citados del artículo, dice:

"A menudo, los mensajes tienen significado, esto es, refieren o están correlacionados de acuerdo con algún sistema con diertas entidades físicas $o$ conceptuales. Estos aspectos semánticos de la comunicación son irrelevantes para el problema de ingeniería" (Shannon 1948, p. 1).

Por el contrario, el foco está puesto en caracterizar estadísticamente la fuente, el receptor y las correlaciones entre ellos, y en cómo codificar mensajes de la manera más eficiente para ser transmitidos por un canal.

Finalmente, hay que remarcar que el significado del término 'información' en esta teoría no está del todo especificado. La teoría de Shannon permite hacer cálculos relevantes para la transmisión de la información de la manera más óptima dadas ciertas características del canal, más que pretender decirnos qué es la información misma. En efecto, algunos filósofos que se han ocupado de la naturaleza de la información han argumentado que la teoría de Shannon por sí misma es incapaz de fijar un significado de la información y que, por lo tanto, requiere necesariamente de una interpretación (Lombardi 2004; Lombardi, Holik y Vanni 2016). 
Varias de estas características de las teorías son relevantes para los argumentos defendidos contra la estrategia importacionista, como veremos en la sección 4.

\title{
3.2. Teoría de la información y biología
}

Durante la década de 1950 hubo algunas aplicaciones explícitas de la teoría de la información para, por ejemplo, determinar la cantidad de información contenida en una secuencia de aminoácidos (Branson 1953), o contenida en una célula bacterial (Linschitz 1953), entre otros. Sin embargo, según Kay (2000), los trabajos de este estilo estaban plagado de problemas: datos desactualizados, asunciones no garantizadas, una numerología dudosa y la incapacidad de generar una agenda experimental. Uno de sus promotores de hecho reconoció muy pronto una derrota:

\begin{abstract}
"La teoría de la información es muy fuerte en un sentido negativo, i. e., en cuanto demuestra lo que no puede ser hecho; como aspecto positivo, su aplicación al estudio de las cosas vivientes no ha producido hasta ahora muchos resultados: no ha conducido al descubrimiento de nuevos hechos, ni su aplicación a hechos conocidos ha sido testeada en experimentos críticos. A la fecha, no es posible un juicio definitivo sobre el valor de la teoría de la información en biología." (Quastler 1958, p. 339)
\end{abstract}

Pero los intentos por mostrar que la TS se aplica adecuadamente continuaron, si bien muy esporádicamente. El libro Information Theory and Molecular Biology (1992), por el físico y teórico de la información, Hubert Yockey, no logró hacer demasiado eco entre filósofos de la biología ni entre 
biólogos. En la misma línea de la objeción de Quastler, Sarkar señala:

"El mayor resultado de la aplicación de la teoría de la información a la biología molecular de Yodkey es que los polipéptidos tal vez no codifican secuencias de $\mathrm{ADN}(\ldots)$. La base de este "teorema" es la degeneración del código genético: una secuencia de polipéptidos dada puede estar codificada en diferentes secuencias de ADN. La condusión es correcta. Lo que resulta misterioso es por qué debe ser invocada la teoría de la información (...) para mostrar un punto tan trivial. Es un hecho trivial combinatorio que ya era conodido por Gamow, Crick o aualquier otra persona que haya pensado en la relación entre el ADN y la proteína” (Sarkar 2005a, p. 195-196).

Aquí conviene trazar una distinción para evitar malentendidos respecto del problema filosófico. Una cuestión es determinar qué aplicaciones útiles tiene la teoría de la información en biología, en relación a determinados contextos investigativos, y los detalles técnicos de su aplicación. Esta cuestión es interesante, pero no es la que genera por sí misma las controversias filosóficas que aquí nos ocupan. Una cuestión muy distinta es, como se vio en la sección 2, si hay un sentido no metafórico, no ficcional, y no puramente epistémico en que podamos afirmar que el ADN (y excepcionalmente algunas otras moléculas relacionadas) son de naturaleza informacional y, en caso afirmativo, si esto puede ser capturado o precisado a partir de la teoría de la información. Una respuesta negativa a lo segundo, por ejemplo, no implica nada respecto de lo primero.

Numerosos filósofos preocupados por el problema tal como aquí lo hemos presentado (cf. Sección 2) han 
atendido a los principales aspectos conceptuales de la teoría de la información y su compatibilidad con las notas distintivas de las descripciones informacionales en biología molecular, muchos arribando a conclusiones negativas. En la siguiente sección, examinaré en más detalle los argumentos que condujeron al consenso en filosofía de la biología de que la teoría de la información no captura adecuadamente el uso de la noción en biología molecular.

\section{CRÍticas Y CONSENSO EN FILOSOFÍA DE LA BIOLOGÍA}

\section{Especificidad}

Un primer argumento tiene que ver con las formulaciones teóricas de Crick (1958) sobre la síntesis de proteínas. En su artículo, Crick se refiere a la información como la "determinación precisa" de la secuencia de bases en el ADN o de los aminoácidos en la proteína, esto es, la especificidad con la que se enlazan ciertas moléculas. La especificidad fue uno de los conceptos centrales de la biología del siglo XX. Sarkar afirma que "durante las primeras tres décadas del siglo, era claro que las interacciones moleculares que ocurrían en los organismos vivos eran altamente "específicas" en el sentido de que moléculas particulares interactuaban con exactamente un reactivo, o unos pocos" (Sarkar 2004, p. 260). Por ejemplo, la especificidad de las enzimas que actúan en la síntesis de proteínas y en la replicación para unirse a sus sustratos, en la especificidad con la que una molécula de ARNt se asocia con cierto aminoácido, la especificidad de la relación de código entre codones y aminoácidos, la especificidad con que se enlazan los nucleótidos entre sí (A-T, C-G), etc. Desde un punto de vista histórico, Kay (2000) sostiene que 
el lenguaje informacional vino a reemplazar el habla de especificidad. Sin embargo, la idea de información en la teoría de Shannon nada tiene que ver con la especificidad de las reacciones en los mecanismos mencionados. La teoría, entonces, no puede capturar esta característica, y no dice nada de cómo la secuencia de componentes de una molécula determina la secuencia de los componentes de otra mediante reacciones específicas (Sarkar 2004). Apelar a teoría de la información implica pasar por alto la conexión con la especificidad, aun cuando dicha conexión no sea del todo evidente.

\section{Probabilidad y cantidad de información}

De acuerdo con la teoría de la información, cuanto más baja sea la probabilidad del estado de la fuente, mayor es la cantidad de información transmitida por ese estado, porque mayor es la incertidumbre que se reduce acerca de la fuente. Inversamente, un estado de probabilidad más alta transmite menos información porque reduce menos la incertidumbre. De acuerdo con Sarkar (2004, 2005c), uno puede hablar de secuencias nucleotídicas más o menos probables en base a distintas consideraciones. Por ejemplo, desde un punto de vista evolutivo, las secuencias más probables en una población (al menos en sentido frecuentista) serían aquellas que más significativamente han afectado a los organismos y que, por lo tanto, han sido aquellas favorecidas por la selección natural. Sarkar advierte que de hecho, en ocasiones, los biólogos se refieren a éstas como aquellas que son informacionalmente más destacables. Pero si esto es así, los estados que más información transmiten serían también los más probables, una situación que entra en conflicto con la relación inversamente proporcional que se 
da entre información y probabilidad en teoría de la información.

\section{Asemanticidad}

Algunos autores han argumentado en contra de la estrategia importacionista a partir del carácter explícitamente asemántico de la teoría de la información (Sarkar 2005a, 2005b, 2005c; Jablonka 2002). Como sabemos, la teoría no dice nada sobre el contenido de la información. Eva Jablonka (2002) plantea el problema considerando tres secuencias de ADN de la misma longitud: una que codifica una enzima funcional, una segunda que codifica una molécula enteramente disfuncional, y una tercera que no interviene en la elaboración de ningún producto ni en la regulación de la expresión de ningún gen. Ella señala que estas tres secuencias serían tratadas del mismo modo desde el punto de vista de la teoría de la información cuando en realidad la idea de información en biología parece vinculada con consideraciones funcionales en base a las cuales dichas secuencias no son equivalentes. Por ejemplo, para el biólogo John Maynard Smith (2000), la idea información genética guarda directa relación con la elaboración de productos funcionales para el organismo y éstos no pueden ser pasados por alto en un análisis filosófico de dicha idea. Si bien función y significado no son lo mismo, están estrechamente vinculados en filosofía, en la medida en que importantes programas filosóficos han buscado naturalizar ciertas nociones semánticas reduciéndolas a aspectos funcionales (Godfrey-Smith 2006). El problema, en síntesis, es que no hay forma de vincular función o significado con teoría de la información. 


\section{Trivialidad}

Una cuarta objeción tiene que ver con el reconocimiento de que la información en el sentido de Shannon "está en todos lados" (Godfrey-Smith 2004). Esto sucede ya que cualquier situación que consista en dos sistemas, cada uno de los cuales capaz de tener distintos estados con determinada probabilidad de ocurrencia asociada, y donde se dé una correlación sistemática entre estados de ambos, califica como situación comunicacional y, por lo tanto, pertenece al dominio de aplicación de la teoría de la información. $\mathrm{Y}$ de hecho un sinfín de situaciones cotidianas son de esta clase. Para algunos, esto implica que la idea de información derivada de la teoría es poco sustancial si lo que persigue el lenguaje informacional en biología es expresar alguna clase de peculiaridad de los factores genéticos $\mathrm{y} / \mathrm{o}$ de los mecanismos en los que intervienen. Decir que los genes llevan información en el sentido de Shannon es decir muy poco, a saber, que entre los genes y sus productos existe una correlación sistemática, lo cual es característico de incontables sistemas, biológicos y no biológicos. Por esta razón, algunos se refieren a esto como un sentido "mínimo" o "débil" de información (Godfrey-Smith y Sterelny 2016), e incluso cuando bien pueda ser el caso que el ADN contiene información en este sentido sigue siendo válida la pregunta de si acaso en biología no se afirma algo más fuerte.

\section{Indistinción ADN-ambiente}

Uno de los argumentos que más discusión ha generado es que la teoría de la información es ciega respecto de la distinción entre ADN y ambiente (Sarkar 2004, 2005c, 2005b; Godfrey-Smith 2004, 2008; Godfrey-Smith y 
Sterelny 2016; Maynard Smith 2000). Más específicamente, la teoría no permite singularizar el $\mathrm{ADN}$, por un lado, y descartar el ambiente, por el otro, en tanto fuentes de información (un problema que podría ser visto como caso particular del problema de la trivialidad). En general, se asume que el genoma es la fuente de información, el fenotipo o los productos génicos más inmediatos (como las proteínas) es el sistema receptor, y el ambiente (celular y/o exterior) se interpreta como el canal por el que se transmite la información genética. Sin dudas, se dan correlaciones sistemáticas entre estados del genoma y estados fenotípicos. Sin embargo, nada en la teoría de Shannon ni su esquema de sistema comunicacional impide hacer un modelamiento distinto, invirtiendo fuente y canal. En tanto haya correlaciones sistemáticas entre el ambiente y ciertos rasgos fenotípicos, el ambiente bien puede ser interpretado como fuente de información. Dado que este es el caso (pues en efecto se dan algunas correlaciones de esta clase), el ambiente el contiene información en el sentido de Shannon acerca del fenotipo tanto como puede afirmarse lo mismo respecto del genoma. Ahora bien, el problema no está en aceptar que hay correlaciones entre elementos del ambiente y rasgos fenotípicos (lo cual ningún biólogo rechazaría), sino que la afirmación de que los genes contienen información, de acuerdo con algunos autores, apunta a expresar algo distintivo de los mismos, algo que el ADN no comparte con cualquier otro factor relevante en el desarrollo. Si esto as así, y la teoría de la información oculta esta distinción, entonces esta estrategia para dar cuenta del concepto de información en biología no es apropiada. 


\section{Consideraciones adicionales}

Aunque las objeciones anteriores son atendibles, hay otras consideraciones más generales que no han sido realmente tenidas en cuenta en la literatura sobre el tema. En primer lugar, etiene el uso de nociones informacionales en biología connotaciones cuantitativas? La pregunta puede parecer menor, pero no es un punto nada menor advertir que, si la respuesta es negativa, entonces apelar a un aparato formal de cálculo para elucidar la noción de información en biología es una empresa filosófica que está mal concebida desde el principio. Todos los argumentos previos pasan por alto este punto. Primero necesitamos acordar que el lenguaje informacional en biología es intrínsecamente cuantitativo (sin importar qué connotaciones adicionales tenga), y esta es una reflexión que no se ha dado. Muy por el contrario, varios trabajos están enfocados en mostrar que las connotaciones más salientes son o bien semánticofuncionales (Maynard Smith 2000; Jablonka 2002; Shea 2007, 2011a, 2011b; Stegmann 2005), o bien causales (Godfrey-Smith 2004; Weber 2006; Stegman 2012), ninguna de las cuales es intrínseca, necesaria, o fundamentalmente cuantitativa (incluso cuando puedan ser complementadas con un abordaje cuantitativo).

En segundo lugar, la filosofía de la biología suele asumir que la teoría de la información ofrece un concepto claro y para nada problemático de información; no en tanto trasladada a la biología molecular (hemos visto en esta sección que sí hay problemas en este sentido), sino tomada en sí misma (ver Sterelny y Griffiths 1999; Griffiths 2001; Downes 2006; Godfrey-Smith 2008; Griffiths y Stotz 2013: 158; Godfrey-Smith y Sterelny 2016. Incluso autores que toman una postura no importacionista (y que, en rigor, no necesitan defender las virtudes de la teoría) suelen referirse a la información de Shannon de esta manera). Esto resulta 
bastante inexplicable, ya que en contextos próximos a la filosofía de la física, así como en el propio ámbito de la recientemente constituida filosofía de la información se discute mucho acerca de la naturaleza misma de la información de Shannon y en qué medida la teoría permite fijar un significado del término 'información'. Algunos filósofos han insistido en el carácter formal de la información de Shannon enfatizando que, como todo aparato formal, necesita ser interpretado (Lombardi 2004; Lombardi, Holik y Vanni 2016). Las interpretaciones de la teoría de la información son realmente variadas, y van desde sostener que la información es algo físico (Brown, 1987; Kosso, 1989; Landauer, 1991; 1996) a defender que 'información' es un término abstracto de masa (Timpson 2004, 2006, 2013). Estas discusiones no han hecho eco en filosofía de la biología, lo que ha redundado en una visión simplista y un tanto ingenua sobre la noción de información que se sigue de la teoría. La asunción de que tenemos una cabal comprensión de la teoría de la información desde un punto de vista filosófico-conceptual quizás sea el resultado de tomar (erróneamente) utilidad y el éxito de la teoría en dominios relativos a las comunicaciones como un indicador de claridad conceptual. Sería ingenuo pretender que una teoría que tiene como objetivo resolver problemas prácticos sea conceptualmente iluminadora, sobre todo tratándose de una teoría formal. Pero es igualmente ingenuo intentar iluminar un concepto elusivo apelando a otro concepto elusivo sin primero abordar este último.

En base a consideraciones como las que hemos visto en esta sección, muchos filósofos interesados en el problema del concepto de información en biología arribaron a la conclusión de que si acaso hay alguna forma de explicar, elucidar, y defender el uso del concepto de información en biología, esto no es alcanzable por medio de la estrategia importacionista. Sin embargo, algunos aportes recientes a la 
literatura sobre el tema parecen desafiar este consenso y vindicar la estrategia importacionista. En la siguiente sección, consideraré dichos aportes y argumentaré que, contrario a las apariencias y promesas, no logran este objetivo.

\section{5. ¿EL IMPORTACIONISMO ATACA DE NUEVO?}

A pesar de los argumentos considerados en la sección anterior, algunos todavía consideran que la teoría de la información puede aún hacer aportes significativos, rehabilitando la discusión contra aquella visión pesimista. Hay dos propuestas muy recientes en esta línea, una que vincula teoría de la información con funciones biológicas, y otra que vincula teoría de la información con especificidad causal. En esta sección, consideraré ambas y mostraré que en ninguno de los dos casos estamos realmente frente a una vindicación de la estrategia importacionista.

\subsection{Teoria de la información y función informacional}

Para varios autores, los problemas más graves para la estrategia importacionista son la indistinción genesambiente y la trivialidad (Bergstrom y Rosvall 2011a, 2011b; Lean 2014). Bergstrom y Rosvall (2011a, 2011b) han propuesto un enfoque que, de acuerdo con ellos, captura mucho de lo que los biólogos quieren decir cuando hablan de la información en los genes y que, además, recupera el espíritu de la teoría de la información, sorteando asimismo aquellos dos problemas. Esta propuesta consiste en una visión de la información centrada en su transmisión, pues insisten en que el problema de la transmisión, esto es, cómo transmitir información del modo más eficiente, es el 
aspecto central de la teoría de la información y sus objetivos. Sus defensores no se proponen definir 'información' sino dar un criterio para decidir en qué casos estamos frente a transmisión de información. De acuerdo con este enfoque,

"un objeto $X$ transmite información si la función de $X$ es reducir, en virtud de sus propiedades secuenciales, la incertidumbre por parte de un agente que observa $X$ " (Bergstrom y Rosvall 2011a, p. 165).

Esta definición, advierten, no debe aplicarse al proceso ontogenético que va de los genes (u otros factores no genéticos) a los fenotipos; es decir, no se aplica al desarrollo de los organismos. La definición no intenta capturar qué significa que un gen contenga información para la síntesis de una proteína. Por el contrario, se aplica exclusivamente a la herencia entre generaciones, que entienden como el único dominio donde se puede hablar de transmisión de información propiamente dicho. Por "agente observador" hay que entender, en este caso, el organismo de la siguiente generación. Bergstrom y Rosvall argumentan a favor de esta restricción de dominio señalando que cuando se habla de 'transmisión' en biología es en referencia a la herencia, no al desarrollo (es decir, no a la idea de que hay información codificada en el genoma que se decodifica en su expresión en un producto fenotípico). El argumento es el siguiente: el problema fundamental del que se ocupa la teoría de la información es el de cómo empaquetar y transmitir eficientemente la información; en biología, por su parte, la transmisión remite a la herencia intergeneracional; por lo tanto, se puede hablar de información propiamente donde hay herencia entre generaciones.

Con esta restricción, el problema de la indistinción genes-ambiente no se suscita, un problema que surge 
únicamente cuando se consideran aspectos ontogenéticos (a los cuales este enfoque renuncia). Bergstrom y Rosvall reconocen que puede haber correlaciones relevantes tanto entre genes y fenotipo como entre ambiente y genotipo, y admiten que si se piensa en la información de Shannon como algo fundamentalmente correlacional, entonces, efectivamente falta un criterio para distinguir genes y factores ambientales. Pero estos autores enfatizan un aspecto distinto de la teoría de la información, que va más allá de las correlaciones confiables, a saber, que trata ante todo el problema de la transmisión. Asumiendo esta perspectiva respecto de la teoría de la información, los autores sostienen que pueden evitar el problema de la indistinción, pues en una visión darwiniana clásica el ambiente no es algo que se transmita intergeneracionalmente.

Bergstrom y Rosvall admiten que ésta quizás es una visión simplificada de los fenómenos biológicos, y consideran algunos casos de herencia no genética, tal como los patrones de metilación del $\mathrm{ADN}^{2}$. Sin embargo, insisten en que este enfoque no pretende descartar otras estructuras como portadoras de información ni afirmar que los genes tengan propiedades únicas y especiales; por el contrario, intenta ofrecer un criterio general para contar una estructura biológica como miembro de la clase de estructuras portadoras de información (una clase que no está a priori constituida exclusivamente por los genes). Así, por ejemplo, concluyen que los patrones de metilación transmiten información de generación en generación, pero

2 Estos patrones o marcas son modificaciones químicas del $\mathrm{ADN}$ relacionadas con la regulación de la expresión génica; en particular, consisten en grupos metilos que se añaden a la citosina "silenciando" la expresión de algunos genes (Alberts et al. 2010). 
lo mismo no es cierto de cualquier elemento extrínseco del ambiente: la temperatura ambiental, por ejemplo, aunque tenga efectos suficientemente confiables y recurrentes sobre los organismos, no se transmite de generación en generación y, por lo tanto, no cuenta como portadora de información. Así, si bien se incluyen algunos ítems que no son del todo estándar, el criterio no se recoge trivialmente cualquier cosa.

Pero aunque el sentido transmisional de información se pretende basado en la teoría de la información, no es tan obvio de qué manera la definición se conecta con la teoría. Por un lado, el interés parece estar puesto en mostrar cómo ciertos aspectos conceptuales de la teoría son, contrario a algunas objeciones, compatibles con ciertos aspectos de la idea de información en biología; por ejemplo, este es el caso de la transmisión, que tendría su análogo biológico en la herencia. Pero ni siquiera en este sentido es absolutamente evidente que la propuesta transmisional se basa en la teoría de la información. En realidad, desde el punto de vista conceptual, la transmisión no es exclusiva de la teoría de la información. No sólo porque la idea de transmisión y la de información aparecen relacionadas hasta en el uso cotidiano de esos términos, sino también porque existen presentaciones de la teoría en términos puramente probabilísticos y que no refieren ni a la fuente, ni al canal, ni al receptor, ni, pues, a la transmisión (ver la formulación sintáctica de Cover y Thomas, 1991). La referencia a la transmisión no basta para trazar una relación concreta entre la definición de Bergstrom y Rosvall y la teoría. De manera semejante, Stegmann (2013) ha objetado que el enfoque no da indicaciones precisas de cómo hay que entender la reducción de la incertidumbre en el caso de los genes y otras estructuras heredables, ni cómo habría que entender otros conceptos incluso más centrales de la teoría, como el de información mutua, en el contexto de la herencia 
intergeneracional (ver Stegmann 2013 para un ensayo respuestas posibles). Pero estas consideraciones serían más relevantes si Bergstrom y Rosvall no llevaran a cabo la restricción de dominio. Los usos paradigmáticos del concepto de información (incluso desde las formulaciones de Crick) no están ceñidos a la herencia entre generaciones. Las principales notas características de uso del concepto de información en biología, vinculados con mecanismos ontogenéticos y la síntesis de productos moleculares, son dejados de lado sin ninguna justificación suficiente. En biología, las referencias a la información genética son relativas a los productos moleculares sintetizados a partir de las secuencias nucleotídicas, de modo que, por más cercana a la teoría de la información que sea la definición de Bergstrom y Rosvall, su propuesta parece, en buena medida, estar cambiando el tema. Simplemente no intenta dar cuenta del concepto de información en biología molecular.

Para Oliver Lean (2014), la propuesta de Bergstrom y Rosvall es incapaz de dar cuenta de una distinción que está a la base de la objeción de trivialidad: aquella entre la información per se y las "funciones informacionales". Concede al consenso anti-importacionista que la información en sentido correlacional, es decir, en sentido de Shannon, "está en todos lados"; sin embargo; aunque muchos factores llevan información en este sentido, sólo un subconjunto de estos tiene la función de llevar información. De acuerdo con Lean, un factor tiene una función informacional cuando es explotado por los sistemas biológicos en la maximización del fitness dado cierto ambiente. De esta manera, se excluyen causas de las variantes fenotípicas que no están correlacionadas con determinados estados ambientales y se sortea la objeción de trivialidad, ya que no cualquier factor relevante para el desarrollo tendrá una función informacional. 
El problema con esta idea es similar al problema del sentido transmisional de información: recupera un aspecto de la teoría de la información, pero al precio de una aplicación que no es del todo congruente con el modo como realmente se habla de información en biología molecular. En este caso, recupera un sentido correlacional de información, pero las descripciones informacionales en biología molecular no tienen mucho que ver con el fitness de los organismos (por ejemplo, este es el caso de las formulaciones de Crick, que bien pueden ser tomadas como ejemplares paradigmáticos). Aunque esta caracterización del uso del concepto de información en biología permita sortear la objeción de arbitrariedad, falla en recoger notas distintivas del mismo.

Estos enfoques buscan recuperar un rol elucidatorio para la teoría de la información, mostrándola (parcialmente) compatible, conceptualmente, con los usos del concepto en biología molecular, al menos en parte. En cuanto a las objeciones del consenso anti-importacionista, intentan mostrar que las objeciones de trivialidad e indistinción no son realmente insuperables, pero no dicen nada acerca de las demás. Más aun, estas reconstrucciones se alejan de los usos paradigmáticos del concepto de información en biología. A continuación, veremos un enfoque bastante diferente que es más cercano a las formulaciones teóricas biológicas y que, en principio, parece desafiar más directamente el consenso.

\subsection{Especificidad causal y teoría de la información}

Partiendo de la intención explícita de basar el análisis en los usos paradigmáticos del concepto de información en biología, un enfoque muy reciente defiende que el discurso informacional en biología molecular no es sino otro modo 
de referirse a la especificidad causal de ciertos procesos y que la misma puede ser cuantificada mediante el formalismo de la teoría de la información (Griffiths et al. 2015; Stotz y Griffiths 2017; Griffiths 2017; Calcott et al. en prensa; Pocheville et al. manuscrito no publicado).

Karola Stotz y Paul Griffiths (Griffiths y Stotz 2013, ch. 4; Stotz y Griffiths 2017) sugieren que la biología molecular originó un nuevo sentido de especificidad, mejor plasmado en el dogma central y en la hipótesis de la secuencia, que no está basado en ninguna clase de consideración estereoquímica (a diferencia del sentido bioquímico de especificidad aludido en la sección anterior. Por el contrario, este nuevo sentido de especificidad "fluye" de una molécula a otra, de modo que es algo que no depende de la constitución ni de la forma de un tipo de molécula. Los defensores de este enfoque proponen analizar esta idea no estereoquímica de especificidad en términos filosóficamente más precisos, a saber, en el marco de la teoría intervencionista de la causalidad (Woodward 2003, 2010). De acuerdo con la teoría intervencionista, las relaciones causales son aquellas potencialmente explotables con fines de manipulación y control, y podemos afirmar que $\mathrm{X}$ causa $\mathrm{Y}$ si y sólo si hay algunas condiciones de fondo $\mathrm{B}$ tales que si una (única) intervención que cambia el valor de X (y no de otra variable) ocurriera en B, entonces $\mathrm{Y}$ cambiaría ${ }^{3}$. Desde este marco es también posible explorar

3 Aquí, la noción de intervención está restringida de varias maneras, aunque en general se trata de una manipulación experimental idealizada llevada a cabo sobre $\mathrm{X}$ tal que el cambio causado en $\mathrm{Y}$ ocurra sólo mediante este cambio en $\mathrm{X}$. Por otra parte, para identificar una relación causal genuina, no se requiere que la intervención tenga lugar de hecho (aunque debe ser concebible) ni que sea ejecutada 
diferentes propiedades respecto de las cuales las contribuciones causales difieren y pueden ser comparadas, como el grado de especificidad causal, que tiene que ver con la posibilidad de obtener un control de grano fino sobre el efecto (Woodward 2010).

La noción de especificidad causal a menudo se explica partiendo de la oposición con las variables causales de tipo "interruptor", que reciben este nombre ya que solo pueden asumir dos valores. En cambio, las variables específicas pueden asumir cualquier valor dentro de cierto rango de posibles valores, $\mathrm{y}$ una intervención en $\mathrm{C}$ puede llevarse a cabo para producir cualquier valor en $\mathrm{E}$ dentro de un rango. Por ejemplo, en un equipo de radio, el botón de encendido sólo puede asumir dos valores (encendido; apagado), y una intervención para fijar dicha variable en cada uno de estos dos valores sólo determina que yo escuche algo o nada. Por el contrario, la perilla del dial puede asumir una amplia gama de valores, con una correspondiente amplia gama de efectos (puedo sintonizar una gran variedad de estaciones). En suma, la especificidad es una propiedad del mapeo entre causas y efectos. En el caso ideal, el mapeo es uno-a-uno o biyectivo, una condición que raramente se cumple en casos reales. Como sea, una relación causal es más específica cuanto más se acerque el mapeo a una biyección.

El siguiente paso del enfoque consiste en proveer una medida de la especificidad causal que, de otra manera, resulta una noción más bien cualitativa (tal que sólo permite afirmar cosas como que $\mathrm{A}$ es causalmente más específico que B). Se parte de la idea simple, pero elegante, de que cuanto más específica es la elación entre $\mathrm{C}$ y E, más información tenemos acerca del efecto luego de llevar a

por agentes inteligentes (procesos naturales pueden contar como intervenciones). 
cabo una intervención en $\mathrm{C}$, y así es como se introduce la teoría de la información. La idea es que se puede medir en qué medida se reduce nuestra incertidumbre acerca de $\mathrm{E}$ al conocer el valor de $\mathrm{C}$ fijado mediante una intervención, $\mathrm{y}$ que podemos comparar la entropía de la distribución de probabilidades del valor de $\mathrm{E}$ antes y después de conocer el valor de $\mathrm{C}$ fijado por mediante intervención. En esta aplicación de la teoría de la información, las relaciones representadas no son ya correlaciones sistemáticas (como en las aplicaciones usuales), sino el efecto en $\mathrm{E}$ de intervenir experimentalmente en C. La idea es que la teoría de la información permite expresar la tendencia hacia un mapeo biyectivo como un continuo.

En este análisis, en síntesis, "las relaciones causales son 'informacionales' simplemente cuando son altamente específicas" (Stotz y Griffiths 2017, p. 367). Pero, al mismo tiempo, para sus defensores, se trata de "un análisis teóricoinformacional de la información biológica" (Stotz y Griffiths 2017):

"Conduimos a partir de estos ejemplos que hay al menos algunos contextos en los cuales el lenguaje informacional es otro modo de hablar del relativamente alto grado de especificidad que se observa en algunos procesos causales en biología (...) en la sección siguiente presentaremos un análisis teórico-informacional de la especificidad. Si el argumento de esta última sección es correcto, entonces lo que se sigue es también un análisis teóricoinformacional de la información biológica" (Stotz y Griffiths 2017, p. 372, énfasis añadido).

Esto sugiere que la propuesta vindica la estrategia importacionista. Sin embargo, a pesar de lo que se afirma, el enfoque no contribuye a realmente rehabilitar la estrategia 
importacionista, y la razón tiene que ver con el rol que la teoría de la información tiene en esta propuesta.

Para comprender dicho rol, concedamos al enfoque sus aspectos reduccionistas, esto es, la tesis de que las descripciones informacionales en biología (o al menos en los casos más representativos o relevantes) no son sino otra forma de referirse a la especificidad causal de las relaciones involucradas. Como hemos visto, los defensores del enfoque sugieren que su propuesta es un análisis teóricoinformacional de la noción de información en biología. En otras palabras, que en la medida en que la teoría de la información es invocada como medida de la especificidad causal, y que información en biología no es sino especificidad causal, entonces el enfoque realmente intenta elucidar el concepto de información en biología. Más aun, el enfoque parece pretender llevar a cabo dicha elucidación a partir de la teoría de la información, que se corresponde exactamente con lo que aquí hemos caracterizado como estrategia importacionista. Parece haber cierto razonamiento transitivo que conecta el habla informacional en biología con la teoría de la información, e interpretar la propuesta de esta manera parece plausible a primera vista. Uno podría intentar argumentar que todo aquello que es medible con teoría de la información merece, eo ipso, el nombre de 'información', y que no importa si esto ocurre via la noción de especificidad causal. Pero esta no es una descripción justa del propósito con el que la teoría de la información es realmente invocada ni, por lo tanto, de la relación entre información en biología, especificidad causal, y teoría de la información en el enfoque de Griffiths et al. Antes bien, en esta línea de razonamiento esconde una sutil trampa cuya exposición requiere analizar más cuidadosamente el papel exacto que la teoría de la información viene a jugar en el enfoque. 
La teoría de la información es introducida en el enfoque para tornar rigurosamente cuantitativa la noción de especificidad causal y es, por esta misma razón, un complemento de la misma. Los efectos de introducir teoría de la información en el enfoque son relativos a la noción de especificidad causal, no relativos a la noción de información en biología. Dicho de otra manera, si la teoría permite refinar algo en absoluto, es precisamente la idea de especificidad causal -al menos, en la medida en que contar con una medida de una propiedad contribuye a refinar nuestro entendimiento de la misma (lo cual podría bien ser discutido).

Por otra parte, el papel que la teoría de la información tiene en esta propuesta no es clarificatorio y no permite dotar de sustancia al lenguaje informacional en biología. Por el contrario, la teoría es utilizada de una forma instrumental. Esto puede no ser tan obvio cuando lo que está en juego es el problema del concepto de información en biología molecular (después de todo, todo aquí parece hablar de lo mismo: información), pero otras prácticas en la misma biología nos sirven para entender este uso instrumental de una teoría formal. En ecología, una noción fundamental para estudiar la estructura de las comunidades es la de diversidad ecológica. Diversidad refiere tanto a la cantidad de tipos que hay en un sistema (por ejemplo, especies) y la distribución de los individuos de cada tipo (esto es, su abundancia relativa). Los ecólogos cuentan con diversas herramientas matemáticas para medir diversidad. Una de las más utilizadas es la que los ecólogos llaman "el índice de Shannon", ya que emplea el formalismo de la teoría de la información para medir diversidad ecológica (Begon et al. 2006, cap. 16). Esta aplicación de la teoría de la información en biología ilustra muy bien lo que he llamado 'uso instrumental', ya que ningún ecólogo afirmaría que al llevar a cabo una medición utilizando el índice de 
Shannon se está, con ello mismo, conceptualizando la diversidad ecológica (o entendiéndola mejor) como información; ellos no están interesados en la transmisión de información dadas las condiciones de un canal, sino en medir el número de especies y cantidad de individuos en un sistema. La medida no implica nada en términos de nuestra comprensión de la diversidad ecológica. Bien por el contrario, la medida presupone cierta comprensión del fenómeno en relación con el cual la misma puede ser evaluada como pertinente.

Más aun, a menudo, hay que detenerse en la consideración de que, en ocasiones, formalismos distintos sirven (presuntamente) un mismo propósito. De nuevo, esto se aprecia en ecología, donde se utilizan otros índices además del índice de Shannon (por ejemplo, el índice de Simpson es tan ampliamente utilizado como aquél y no está basado en teoría de la información). Esta es otra consideración que muestra que apelar a una teoría formal para obtener una magnitud no equivale a apelar a una teoría formal para conceptualizar, comprender mejor, o elucidar la propiedad. La relación entre información (en teoría de la información) y diversidad es contingente a la elección de un índice en lugar de otro. ¿Por qué sería diferente en el caso de la especificidad causal?

La moraleja para mí es la siguiente: invocar teoría de la información para tornar cuantitativa la noción de especificidad causal no equivale a invocarla con propósitos clarificatorios, i.e., para elucidar el habla informacional en biología. Tampoco equivale a ofrecer una justificación o defensa del uso de nociones informacionales en biología, pues frente a la reducción de información a especificidad causal la pregunta es: ¿qué fundamentos conceptuales hay para referirse a relaciones altamente específicas como informacionales? La respuesta a este tipo de preguntas debe ir más allá de constatar meros usos de hecho o 
incurriríamos en una petición de principio. No podemos citar el hecho de que ciertas relaciones causales en ciertos contextos biológicos sean, de hecho, descriptos en términos informacionales como explicación de este mismo hecho o como justificación filosófica para hacerlo. Esta es una cuestión de iure: queremos qué fundamentos conceptuales hay para referirnos a ciertas relaciones causales biológicas como 'informacionales' (si alguno), pero, nuevamente, ninguna justificación del estilo se sigue del enfoque de Griffiths et al.

En suma, el enfoque no logra defender el uso de nociones informacionales por la vía importacionista, porque ni la reducción del lenguaje informacional en biología al lenguaje de la especificidad causal, ni la propuesta de medir especificidad causal mediante teoría de la información bastan para afirmar que el enfoque elucida y defiende las descripciones informacionales en biología en términos de la teoría de la información.

\section{CONCLUSIONES}

En este artículo, he presentado una reconstrucción del problema en torno al concepto de información en biología molecular de una forma sistemática y abarcadora. Así definido el problema, delineé las dos estrategias principales para abordarlo. Fundamentalmente, me ocupé aquí de la estrategia importacionista en el contexto de recientes aportes a la literatura filosófica sobre el tema. Primero, analicé los argumentos usualmente erigidos para desestimar la relevancia de la teoría de la información para abordar el problema, e introduje algunas consideraciones adicionales a dichos argumentos que no han sido tenidos en cuenta en el debate. Luego, presenté dos propuestas que vuelven a poner la teoría de la información en el centro de atención y 
que podrían ser vistas como rehabilitando la debilitada estrategia importacionista. La tesis que sostuve es que incluso la propuesta más refinada en esta línea falla en vindicar la estrategia importacionista y que, como consecuencia, el consenso todavía puede ser defendido. Pero aunque estos casos en particular fallen, logran mostrar que la discusión no está tan saldada como podría parecer.

\section{REFERENCIAS}

ADriaAns, P. "Information", The Stanford Encyclopedia of Philosophy, Edward N. Zalta (ed.), URL = http:/ / plato.stanford.edu/archives/ fall2013/entries /information/, 2013.

AlBERTS et al. Biología molecular de la célula (5ta. Edición). Barcelona: Omega Ediciones, 2010.

BEGON, M. et al., Ecology. From individuals to ecosystems (4ta. Edición). Oxford: Blackwell Publishing, 2006.

Bergstrom, C. y Rosvall, M. "The transmission sense of information”. Biology \& Philosophy, 26, pp. 159-176, 2011a.

"Response to commentaries on "The Transmission Sense of Information". Biology \& Philosophy, 26, 2, pp. 195-200, 2011b.

Bogen, J. y MACHAMER, P. "Mechanistic Information and Causal Continuity". En Causality in the Sciences, editado por Phyllis Illari, Federica Russo y Jon Williamson, 845-864. Oxford: Oxford University Press, 2011.

BRANSON, H. R. "A definition of information from the thermodynamics of irreversible processes", en: 
Quastler, H. (ed.), Essays on the use of information theory in biology. Urbana: University of Illinois Press, pp. 2540, 1953.

BROwn, H.I. Observation and Objectivity. New York/Oxford: Oxford University Press, 1987.

CALCOTT, B. "The Creation and Reuse of Information in Gene Regulatory Networks". Philosophy of Science 81(5): 789-890, 2014.

Griffiths, P. y POCHEVILLE, A. (Forthcoming). "Signals that make a difference". British Journal Philosophy for the Philosophy of Science: https://doi.org/10.1093/bjps/axx022.

COVER, T. y Thomas, J. Elements of Information Theory. New York: JohnWiley \& Sons, 1991.

CrICK, F. "On Protein Synthesis", Symposium of the Society of Experimental Biology, 12, pp. 138-163, 1958.

Downes, S. "Biological Information." In Pfeiffer and S. Sarkar (Eds.) Philosophy of Science: An Encyclopedia. New York: Routledge, pp. 64-68, 2006.

EMmeCHE, C. "A semiotical reflection on biology, living signs and artificial life", Biology \& Pbilosophy 6(3): 325340, 1991.

"The Sarkar challenge to biosemiotics: Is there any information in a cell?", Semiotica 127 (1/4): 273-293, 1999.

FLORIDI, L. "Semantic Conceptions of Information", The Stanford Encyclopedia of Philosophy, Edward N. Zalta (ed.), 2004, URL = $<$ http:/ / plato.stanford.edu/archives/spr2014/entrie $\mathrm{s} /$ information-semantic/ $>$. 
Fox KELLER, E. Making Sense of Life. Explaining Biological Development with Models, Metaphors, and Machines. Cambridge: Harvard University Press, 2003.

GODFREY-SMITH, P. "Genes do not encode information for phenotypic traits", en: Hitchcock (ed.), Contemporary debates in philosophy of science, Oxford: Blackwell Publishing Ltd., pp. 259-274, 2004. "Information in Biology", in: Hull, D., y Ruse, M. (Eds.), The Cambridge Companion to the Philosophy of Biology. Cambridge: Cambridge University Press, pp. 103-119, 2008.

y Sterelny, K. "Biological Information", The Stanford Encyclopedia of Philosophy, Edward N. Zalta (ed.) 2016, URL $<$ https:/ / plato.stanford.edu/archives/sum2016/entr ies/information-biological/ $>$.

GRIFFITHS, P. "Genetic, epigenetic and exogenetic information in development and evolution." Interface Focus 5:1-8, 2017.

"Genetic Information: A Metaphor in Search of a Theory”. Philosophy of Science, 68, 3, pp. 394-412, 2001. , Pocheville, A., Calcott, B., Stotz, K., Kim, Hyunju, y KNIGHT, R. (2015). "Measuring Causal Specificity." Philosophy of Science, 82(4), 529-555, 2015.

, у STOTZ, K. Genetics and Philosophy: An Introduction.

New York: Cambridge University Press, 2013.

Hallyn, F. (ed.) Metaphor and analogy in the sciences. Netherlands: Springer, 2000.

HOFFMEYER, J. Biosemiotics: An Examination into the Signs of Life and the Life of Signs. Scranton: University of 
Scranton Press, 2008.

JABLONKA, E. "Information: Its Interpretation, Its Inheritance and Its Sharing." Philosophy of Science, 69, pp. 578-605, 2002.

KAY, L. Who Wrote the Book of Life? A History of the Genetic Code. Stanford, CA: Stanford University Press, 2000.

KJosAviK, F. "Genes, Structuring powers and the Flow of Information in Living Systems." Biology and Philosophy 29 (3): 379-394, 2014.

Kosso, P. Observability and Observation in Physical Science. Dordrecht: Kluwer Academic Publishers, 1989.

KUMAR, L. "Information, Meaning, and Error in Biology.” Biological Theory 9: 89-99, 2014.

Landauer, R. "Information is physical". Physics Today, May, pp. 23-29, 1991.

"The physical nature of information". Phys. Lett. A, 217, pp. 188-193, 1996.

LEAN, O. "Getting the Most out of Shannon Information". Biology \& Philosophy 29(3), pp. 395-413, 2014.

LEVY, A. "Information in Biology: A Fictionalist Account". Noûs, 45(4): 640-657, 2011.

LINSCHITZ, H. "The information content of a bacterial cell', en: Quastler, H. (ed.), Essays on the use of information theory in biology. Urbana: University of Illinois Press, pp: 251-262, 1953.

LOMBARDI, O. "What is information?" Foundations of Science, 9, pp. 105-134, 2004.

, Holik, F., y VANNI, L. "What is Shannon information?” Synthese, 193(7): pp. 1983-2012, 2006. 
Maynard SMITH, J. "The concept of information in biology". Philosophy of Science. 67, pp. 177-194, 2000.

"Reply to Commentaries". Philosophy of Science 67(2): 214-218, 2000b.

Planer, R. "Replacement of the 'Genetic Program' Program." Biology and Philosophy 29: 33-53, 2014.

"Are Genetic Representations Read in Development?" The British Journal for the Philosophy of Science67: 997-1023, 2016.

Pocheville, A., Montévil, M., STOTZ, K., y Griffiths, P. "Crick information: giving substance to biological information" (unpublished manuscript).

QUASTLER, H. "The status of information theory in biology: a round-table discussion", en: Yockey, H. (ed.), Symposium on information theory in biology. New York: Pergamon Press, pp. 399-402, 1958.

SARKAR, S. "Genes Encode Information for Phenotypic Traits", en: Hitchcock, C. (Ed.), Contemporary Debates in Philosophy of Science, Oxford: Blackwell Publishing Ltd., pp. 259-274, 2004.

"Decoding "Coding": Information and DNA", en: Molecular Models of Life. Philosophical Papers on Molecular Biology. Cambridge: The MIT Press, 2005a.

("Biological Information: A sceptical Look at Some Central Dogmas of Molecular Biology", en: Molecular Models of Life. Philosophical Papers on Molecular Biology. Cambridge: The MIT Press, 2005b.

"How Genes Encode Information for Phenotypic Traits", en: Molecular Models of Life. Philosophical Papers on Molecular Biology. Cambridge: The MIT Press, 2005c. 
"Genes Encode Information for Phenotypic Traits". En Contemporary Debates in Philosophy of Science, editado por Christopher Hitchcock, 259-274. Oxford: Blackwell Publishing Ltd., 2004.

"How Genes Encode Information for Phenotypic Traits". En Molecular Models of Life. Philosophical Papers on Molecular Biology. Cambridge: The MIT Press, 2005.

SHANNON, C. "The Mathematical Theory of Communication”. Bell System Technical Journal 27, pp. 379-423, 1948.

SHEA, N. "Representation in the Genome and in other Inheritance Systems". Biology and Philosophy, 22, pp. 313-331, 2007.

Shea, N. "Developmental Systems Theory Formulated as a Claim about Inherited Representations. Philosophy of Science, 78(1), pp. 60-82, 2011a.

"What's Transmitted? Inherited Information". Biology and Philosophy, 26, 2, pp. 183-189, 2011b.

STEGMANN, U. Genetic information as instructional content. Philosophy of Science, 72, 3, pp. 425-443, 2005. "Causal Control and Genetic Causation. Nô̂s, doi: 10.1111/j.1468-0068.2012. 00867.x, 2012.

"On the 'transmission sense of information'. Biology and Philosophy, 28, 1, pp. 141-144, 2013.

Sterelny, K. y Griffiths, P. Sex and death. An introduction to philosophy of biology. Chicago: The University of Chicago Pres, 1999.

STOTZ, K., y Griffiths, P. "Biological Information, causality and specificity - an intimate relationship." In Sara Imari Walker, Paul Davies, and George Ellis 
(eds.), From Matter to Life: Information and Causality. Cambridge: Cambridge University Press (pp. 366390, 2017).

ŠUSTAR, P. "Crick's Notion of Genetic Information and the 'Central Dogma' of Molecular Biology". The British Journal of Philosophy of Science 58(1): 13-24, 2007.

Timpson, C. "The Grammar of Teleportation." The British Journal for the Philosophy of Science, 57: 587-621, 2006.

Quantum Information Theory and the Foundations of Quantum Mechanics. Oxford: Oxford University Press, 2013.

Quantum Information Theory and the Foundations of Quantum Mechanics. PhD diss., University of Oxford (quant-ph/0412063), 2004.

WeBER, M. "The Central Dogma as a Thesis of Causal Specificity." History and Philosophy of the Life Sciences, 28 (4): 595-609, 2006.

WOODWARD, J. "Causation in biology: stability, specificity, and the choice of levels of explanation." Biology \& Philosopby 25:287-318, 2010.

Making things happen: a theory of causal explanation. Oxford University Press, New York, 2003.

YOCKEY, H. Information theory and molecular biology. Cambridge (UK): Cambridge University Press, 1992.

\section{(c) $\mathrm{EY}$}

